\title{
The Enlightenment of Academy Education to Modern Education against the Background of Emerging Engineering Education
}

\author{
Chen Shuying \\ Key Laboratory of Intelligent Information Processing in \\ Universities of Shandong \\ Shandong Institute of Business and Technology \\ Yan Tai ,China \\ 304779566@qq.com
}

\author{
Chen Lei \\ Coal Economy Academy \\ Shandong Institute of Business and Technology \\ Yan Tai ,China \\ chen177@163.com
}

\begin{abstract}
With the increasing demand for high-quality educational resources, the quality of education has been paid more and more attention. Based on the study of academy education, which is popular for thousands of years, this paper analyzes the educational concept of academy education, especially the characteristics of moral education, the integration of knowledge education and practice education, and the measure of advocating free and open academic atmosphere is widely used in the reform of modern educational ideas and educational models. New curriculum reform is being carried out throughout the country, it is useful to explore the educational concepts contained in the unique culture of academy education and formed in the long-term development. It can enlighten the middle school education based on the new curriculum standard and promote the scientific development of modern university education.
\end{abstract}

Keywords-Academy education; Modern university; New curriculum reform; Teaching students in accordance with their aptitude; Emerging Engineering Education

\section{INTRODUCTION}

Academy is an ancient education institution in China. It began as a local education organization, first appeared in the Tang Dynasty, and the formal education system was founded by Zhu Xi and developed in the Song Dynasty. Academy education is a unique form of educational organization independent of official learning. In the long practice and development, it has formed the characteristics of stereoscopic, democratic, open, innovative, practical and so on, which is unique in the history of the development of ancient Chinese educational thought.

\section{ACADEMY TEACHING IS AN EFFECTIVE SUPPLEMENT TO THE TRADITIONAL SCHOOL PHILOSOPHY}

Ministry of Education General Program of Humanities and Social Sciences. The new round of basic education curriculum reform in our country has done through twenty years, and the vast number of educators have carried out the new curriculum reform in a single day for twenty years, and achieved encouraging results. Looking at the revision of curriculum standards, we found that particular emphasis was placed on the inheritance of Chinese traditional culture. Apart from official education, a unique form of educational organization--academy which had the brilliant course once let us calm down to reflect, we found that it was still beneficial to the new curriculum reform in China [1].

On the whole, the curriculum and teaching of official study are rather complicated and rigid, too stylized, while the curriculum and teaching of academy are simple and flexible, and teachers and students have more initiative and freedom.

When Mao Zedong established Hunan Self-study University in his early years, he used the tradition of the ancient academy for reference. He affirmed that the academy was simple in curriculum, flexible in teaching, discussed by teachers and students together, leisurely, harmonious in feeling and far superior to official learning [2].

From its nature, the academy is the combination of official and private studies, it inherited the fine tradition of official and private studies, but it is not completely one of them.

First of all, the academy is a cultural and educational institution founded and presided over by Confucian literati. Therefore, the academy is open to the lower classes. Its students are not restricted by their status and region, and they have a strong civilian color. Public schools take the official family child as the education object, mainly face the upper class society. Therefore, from the establishment of the academy and the recruit, the two are fundamentally different. Secondly, private school originated in the Spring and Autumn period and was founded by Confucius, and academies were founded by private funding, and oriented to the lower level of society. On the other hand, private school was generally in a state of spontaneity and did not form a complete educational system, while the academy is an organized and well-structured educational system

Therefore, academies are not official schools, but there are some elements of official school, not private, but learn from some of the practices of private school. Through the sublation of the two, the academy gradually formed a unique educational system, which ran through every period and every aspect of its existence and development.

From the point of view of educational system, Academy is a multi-level comprehensive educational system, which included basic education and higher education, and made them better link up. 
The single level of education is an obvious defect of Chinese traditional education system, which is manifested in the serious disconnection between higher education and basic education. In order to develop higher education, the basic education was suppressed [3]. In this case, the basic education was founded spontaneously by the folk, and its function and influence was very limited. However, basic education played an important role in the whole social and cultural development, and the improvement of national quality. With the improvement of social civilization, promoting the development of basic education has become an inevitable trend of historical development. Academy broke the disjointed situation between higher education and foundation, and formed a multi-level educational system, including both, thus it further promoted the rational development of education, especially the basic education. It has a wide and profound social significance to the traditional educational concept of breaking learning in the official school.

From the educational function, the academy closely linked educational teaching and academic research, the two complemented each other. the academy taught students in accordance with their aptitude, and Promoted teaching and learning each other that the academies' characteristics of teaching and learning are mainly based on students autonomic learning, and teachers' taught is complementary, the famous teachers sum up many principles, procedures and methods of study according to their own academic experience, which can help students improve their learning efficiency. Students should keep a reading diary recording their own learning experience, and be good at questioning and debate.

At the same time, the academy carried out free lecture, free listening, and the combination of speech and theory. In the Ming Dynasty, the system of lecture was formed. In the lecture session, the emphasis was placed on the theory of equality, thereby enhancing academic accomplishment and achieving the goal of mutual learning and upgrading. This interactive teaching method between teachers and students is very helpful to the publicity and cultivation of personality. On the other hand, The conference system also provided an opportunity for academic exchanges, enabled academies to break down their opinions and integrate the strengths of various academies. Therefore, Hu Shi believed that "the level of academies in our country can be better than that of foreign universities and academies."

From the point of view of management, academy adopted a democratic management mode, which showed the spirit of 'humanization'. First, the manager of college organization, usually also has the higher academic level and the teaching experience expert or the lecture teacher, the management personnel apart from the teaching is relatively few, promoted the academic exchange greatly at that time. Secondly, from the beginning of the Song Dynasty, students took care of themselves and participated in the management.

From the point of view of teacher-student relationship, the harmonious relationship between teachers and students is an important reason for the outstanding educational achievements of ancient academies. The famous teachers of the academy not only had some academic achievements, but also set a good example for the students with their own practical actions. The fundamental reason why academies formed such a harmonious teacher-student relationship lied in the fact that most ancient academies used the same way of eating and living together. In daily life, the teachers taught personal experience, cared for students, teachers and students established a good relationship. This good atmosphere is conducive not only to the development of teaching activities, but also to develop students personality. Zhu $\mathrm{Xi}$ attached great importance to cultivating the feelings of teachers and students. He got along well with the students and was deeply respected by the students. After his death, the students still remembered him for a long time. In order to inherit the profession, his disciples built their own academies or taught in academies to recruit students.

\section{THE CULTURAL CONCEPT OF ANCIENT CHINESE ACADEMY}

In the Song Dynasty, Chinese academies really developed vigorously. At that time, the status of academy even exceeded the trend of official education, the number, scale, system of maturity can be called unprecedented. Looking at the academy culture in Song Dynasty, Jiangxi Academy is particularly important and has made great contributions to the construction of the academy. It not only appeared the germination of the academic educational form, but also opened the trend of institutionalization and scale of the academy. As a form of educational organization independent of official education, the academy established a new educational model since its establishment. The cultural concept of the academy consisted of the following three aspects:

\section{A. The educational concept of moral education}

In the Song Dynasty, the number of imperial examinations greatly increased and promoted the prosperity of study. However, the purpose of the imperial examination was to transfer management talents for the imperial court. In the long run, the shortcomings of the imperial examination became more and more serious. Different from the official study, the academy always put moral education in the first place and consciously assumed the social responsibility of rectifying the world style. At one time, academies in Song Dynasty became an important base for preaching Neo-Confucianism. Neo-Confucianism standed for being upright, sincere and self-discipline as the foundation of learning. It must take " morality and justice " as the religion, "university", "the mean" as the body, " Confucius " and "Mencius" as the method, and constructed the basic system and framework of Neo-Confucianism. Zhu Xi is the master of NeoConfucianism, personally presided over the Bailu Dong Academy, and personally drawn up the Bailu Dong Academy rules[4]. In the rules, it is clear that "father and son have kinship, monarch and subject have righteousness, couple are different, respect the old and cherish the young, friends have faith", which is full of strong ethical and moral concepts. Under the influence of this kind of educational idea, each academy taked the Confucian classic teaching material as the teaching content, puts " rational " in the first place of education, paid attention to the moral edification to the student. 


\section{B. Free and open school philosophy}

Zhu Xi invited Lu Jiuyuan, who held different academic views, to speak to the Bai Lu Dong Academy on the chapter, "the superior man is the name of the gentleman and the small man is the name of the profit", opened the first stage in which different schools gave lectures at the Academies. A new style of freedom and openness has been established. As a result, academies walked out of a different way from the official schools. In the academy, teachers and students chose each other. Teachers can give lectures freely, and students can choose teachers too. Students got along well with each other. In the specific teaching process, the academic education attached great importance to the guiding role of teachers, guiding students to read and self-study. Students can question teachers and students to solve problems, sometimes even argued with each other. In addition, students and students, or between teachers and friends, also discussed knowledge with each other. While lecturing at Bailu Dong Academy, Zhu Xi often personally questioned and asked the students. From this, we can see that academy lecture is not a simple teaching method, its teaching mode can be summed up as "self-study of studentsteacher explanation-teacher discussion"; This kind of teaching characteristic fully respected the students' individuality, the teacher was not the spoon-fed irrigation education, but played the leading role, the emphasis is to inspire the student, thus has formed one kind of exchange dialogue atmosphere in the whole teaching process.

\section{The practice concept of the unity of knowledge and action}

The academy paid attention to the Integration of knowledge and practice in education, which included the practice of ethics as well as the pursuit of truth and pragmatism in academic. Zhu Xi, a great confucian in the Song Dynasty, paid attention to the combination of theory and practice. He taught the students from the aspects of daily life, etiquette, leisure and so on. In the process of moral education, students were asked to put their moral knowledge into practice. Offering sacrifices to the first saints is an important part of the ritual activities of the academy, and also an important part of the moral practice. Through preaching the moral quality and academic accomplishment of the sages, the students can take the moral personality of the sages and the former as the model, and then cultivated their own sentiment, and realized the perfect unification of moral education and practice. In addition, the academy recognized that the education of students should not be confined to the classroom, but also to a wide range of knowledge outside of books. Zhu Xi often led his students through practical activities during his stay at Bailu Dong Academy, visiting famous mountains and rivers, or visiting famous person, who taught and enjoyed his education. Finally, the academy encouraged the unification of theory and practice, advocated the practical application of the world, and opposed the deviation from reality [5].

\section{THE ENLIGHTENMENT OF ANCIENT CHINESE ACADEMY CULTURE TO THE IDEA OF RUNNING A SCHOOL}

The academy has existed in China for nearly a thousand years, and accumulated a unique cultural concept. The academy contained rich and valuable educational thought. It can undoubtedly enlighten the construction of the idea of running a school to study the cultural idea of academy and take its essence under the new curriculum reform.

\section{A. Establishing a people-oriented teaching concept throughout the college culture concept}

Academy education is a kind of all-round training of human education, which paid attention to the training of mind and ability At present, the people-oriented concept of development has been deeply rooted in hearts, all work is actively carried out, education is to train social activities, there is no exception. In the outline of the National Medium- and Long-Term Education Reform and Development Plan (2010-2020), the strategic theme of educational development is to adhere to the people-oriented approach and to carry out quality-oriented education in an allround way. Its core is to solve the problem of who should be trained and how to train people[6]. In practice, all of them bear the great pressure of the entrance examination and college entrance examination up to the principal, down to the students. Examination scores have become the focus of education, and people are further away from the essence of education. In middle school education, it is necessary to carry forward the peopleoriented education concept and regard people as the starting point of education. Adolescence is an important period for the formation of sense of worth, which is highly plastic, but it is easy to go astray because of their own rebellious psychology. With the rapid development of modern information technology and the wide spread of the number of channels for information dissemination, it is hard to imagine how fast it is for young people to come into contact with extremely bad information, which makes moral education more urgent. Therefore, we must insist on moral education and guide students to form correct values in middle school education. The present school moral education is weak, the limited ideological and moral lesson, the class meeting lesson are the formality, the school rule, the class rule is empty. In order to enhance the timeliness of moral education, we must make full use of teaching resources and carry out rich and varied moral education. What is more crucial is to improve the comprehensive quality of teachers, especially the teachers in charge of class, whose moral quality greatly affects the realization of moral education task

\section{B. Creating an interactive and open classroom atmosphere}

The teaching method of ancient academy in our country can be expressed as narration in modern teaching theory terms, students are self-taught, and teachers and students got along with each other harmoniously. One of the goals of the new curriculum reform is to advocate constructive learning, to realize active participation, and to explore and find out that the learning mode of communication and cooperation, that is, teacher-led and student-oriented, it is similar to the teaching method of the academies to a certain extent. However, many teachers found it difficult to build such a classroom. There is still a big gap between the traditional classroom and the classroom advocated by the new curriculum reform. What role should teachers play in the classroom and how should students participate? These are all problems. The Trinity goal of the new curriculum (knowledge skills, process methods, emotional attitudes and values) requires students to participate in the formation of knowledge, which is bound to allow dialogue between students and teachers, students and students. Teachers play a leading role in teaching, let students enter the classroom as participants, students can find problems before class, or in the process of learning, and then exchange discussions with teachers and classmates. Teachers can also organize various kinds of classroom discussions, let students feel that they are the main body of the classroom, produce a sense of belonging, and then improve their learning enthusiasm. Of course, 
classroom teaching should pay attention to enlighten students from many aspects and make appropriate suggestions. The communicative learning between teachers and students formed an open and interactive classroom atmosphere, which is helpful for students to form open thinking and fully exploit their own potential.

\section{Building the training mode of lifelong learning}

In the process of teaching and learning, academy education paid attention to students subjectivity and was good at tapping students learning potential. Academy students were guided by the method of reading, and constantly gained new knowledge. In pedagogy, it is pointed out that man is an individual of sustained development, that is to say, the learning accompanied the whole life. Compared with a person life, short school education played a limited role after all. In the 1960s, the term "lifelong education" rose, and a new concept of education appeared. Middle school education is the foundation of education stage and the key to lay the foundation of lifelong education. At this stage, we need to encourage students to develop active learning and learning habits. Students often lack motivation and even get tired of what they have learned. Most of the reason is that the teacher can not play a guiding role. If teachers can teach students the true meaning of active learning in the daily teaching process, then school education will be greatly improved. This also means that the education under the new curriculum reform situation has undoubtedly put forward a more severe challenge for the majority of teachers. Teachers should not only train students to establish the concept of lifelong learning, but also make lifelong learning a basic professional quality. Only when a teacher becomes a model of lifelong learning can students be affected. In addition, from the point of view of students own development, the school should set up a platform for students to cultivate comprehensive quality, guide students to participate in various practical activities actively, and realize the effect that classroom activities can not achieve.

\section{The ENLIGHTENMENT OF ANCIENT ACADEMIES to THE CURRENT EDUCATIONAL REFORM IN CHINA}

\section{A. Carry out the mode of running a school with diversified subjects}

The task of education is to improve the quality of the whole nation, and the realization of this goal is far from enough relying on the strength of the government. It also needs the support of society, enterprises, groups and individuals. Private education is an indispensable part of a sound educational system. Therefore, while vigorously developing public education, we should actively support the development of private education, prosper educational and cultural undertakings, and inject new vitality into public education in order to improve the overall quality of education.

\section{B. Integrate the multi-level education system}

For a long time, the basic education has focused on the transition rate, while higher education was concerned with the selection of outstanding talents, which made the whole education system disjointed. The ancient academy system has changed the pattern of separation between official and private studies, higher education and basic education in the traditional education system of our country. From the perspective of the future development trend, it has given a mirror to the contemporary higher education. It is the need of educational development in the new period and the premise of the development of contemporary higher education to integrate the multi-level educational system and to link up and balance the development of basic education and higher education. The first is to establish a unified talent training goal for the two major educational systems, the second is to link up the concept of running a school between the two, putting the moral education in the first place, and the third is to scientifically arrange the teaching content of education, and higher education should reflect the law of the development of modern education. We should pay attention to the cultivation of the learning ability and the individual choice and personality.

\section{CONCLUSION}

The experience accumulated in the course of academy occurrence and development is a valuable asset in the history of education in China, It is worth inheriting and developing selectively. Today education is facing the challenge of knowledge economy, and there are many practical problems. We must reform the concept of education, teaching methods, teaching mode and so on. Under the new historical conditions, we should give new vitality to the precious experience of college and have a positive impact on educational reform.

\section{ACKNOWLEDGMENT}

It is sponsored by National Natural Science Foundation of China (No. (61672327,61602277,61772319,61773244))

The Natural Science Foundation of Shandong Province of China (No. (ZR2014FL007))

The High Level Application Oriented Key Project Construction Specialties of Shandong Province of China

Applied Talents Training Professional Development Support Program in colleges of Shandong Province of China (No. (5001015-34401))

Research on Teaching Reform of Undergraduate Colleges and Universities of Shandong Province in 2016

Teaching Reform and Research Project of Shandong Institute of Business and Technology in 2017 (No. (11688G201715))

Co-innovation Center of Shandong Colleges and Universities : Future Intelligent Computing

2018 Ministry of Education General Program of Humanities and Social Sciences(No.18YJA630011)

\section{REFERENCES}

[1] Dang Tingjun,Evolution of Teaching Characteristics of Acadmy of Classical Learning in Ming and Qing Dynasties and Historical Enlightenment,Journal of China University of Mining \& Technology(Social Science)PP.8993,April,2010.

[2] Chen Jin-su "On the Teaching Management System of Academies in the Song Dynasty", Journal of Hanjiang Normal University:PP. 120-124, February 2018

[3] Gu Hongyi, "A Study of the Late Southern Song Dynasty Department Grant Academy Mountain Long Examination System" , Journal of Hunan University(Social Science),vol. 31, pp. 45-47, Nobember 2016.

[4] Dong Jian, "New Construction and Practice of Anding Academy's Teaching Culture", Jiangsu Education Research: pp.20-23,July 2017.

[5] Wang Zhongyuan,A Study on Wang Yangming's thoughts of Restoration of conscience in Ancient Academy Education,University Education Science:pp.81-86,June 2016.

[6] Zhang Jinsong, "A Textual Exploration in the Starting Time of the Teaching Activities of Bailudong Academy in the Ming Dynsty," Journal of Yangzhou University(Higher Education Study Edition,January 2015. 